\title{
Formulation and Characterization of Fenofibrate Loaded Solid Dispersion with Enhanced Dissolution Profile
}

\author{
Milon Kumar Ghosh1,2, Mir Imam Ibne Wahed1', Md. Ashraf Ali³, Ranjan Kumar Barman1* \\ ${ }^{1}$ Department of Pharmacy, Faculty of Science, University of Rajshahi, Rajshahi, Bangladesh \\ ${ }^{2}$ Department of Pharmacy, Faculty of Biological Sciences, Islamic University, Kushtia, Bangladesh \\ ${ }^{3}$ Department of Pharmacy, Mawlana Bhashani Science and Technology University, Tangail, Bangladesh \\ Email: *drbarman76@gmail.com
}

How to cite this paper: Ghosh, M.K., Wahed, M.I.I., Ali, M.A. and Barman, R.K. (2019) Formulation and Characterization of Fenofibrate Loaded Solid Dispersion with Enhanced Dissolution Profile. Pharmacology \& Pharmacy, 10, 343-355.

https://doi.org/10.4236/pp.2019.107028

Received: June 24, 2019

Accepted: July 28, 2019

Published: July 31, 2019

Copyright $\odot 2019$ by author(s) and Scientific Research Publishing Inc. This work is licensed under the Creative Commons Attribution International License (CC BY 4.0).

http://creativecommons.org/licenses/by/4.0/

\section{(c) (i) Open Access}

\begin{abstract}
Fenofibrate (FF) is an anti-hyperlipidaemic drug belonging to BCS class-II (low solubility, high permeability). Its bioavailability is limited by the dissolution rate. This study was aimed to enhance the rate of dissolution of poorly water soluble drug, FF. Initially, solid dispersions of fenofibrate (SDFs) were formulated with Carplex- 80 or PEG- 4000 or in combination at various weight ratios and were subjected to dissolution study. On the basis of drug release at various time intervals, the formulation producing maximum drug concentration was evaluated physicochemically using differential scanning calorimetry (DSC), powder X-ray diffraction (PXRD), Fourier-transform infrared spectroscopy (FTIR), and scanning electron microscopy (SEM). It was observed that the peak drug concentration was obtained at $120 \mathrm{~min}$ of dissolution by formulation SDF-7, which contains a mixture of Carplex-80 and PEG-4000 at weight ratio 1:5:6 of FF:PEG-4000:Carplex-80, respectively. Thus, the extent of drug release by SDF-7 was maximized by 2.5 -fold than that of pure FF. Physicochemical characterization revealed the reason for this increased drug release as a conversion of crystalline $\mathrm{FF}$ to amorphous form and ensured the chemical compatibility among FF and carriers. The results specified the significant improvement of FF release using solid dispersion technique.
\end{abstract}

\section{Keywords}

Fenofibrate, Solid Dispersion, Dissolution, Solvent Evaporation, Carplex-80, PEG-4000

\section{Introduction}

Oral administration is the simplest and most convenient method to deliver drugs 
[1]. Unfortunately, poor aqueous solubility leading to inadequate dissolution of some drugs is a crucial barrier for oral drug delivery and it causes poor gastrointestinal absorption resulting in low and variable bioavailability [2]. It was reported that $40 \%$ of drugs from newly developed chemical entities are poorly soluble in water, among which $10 \%$ fail to reach the market, although these drugs possess high membrane permeability [3]. According to Biopharmaceutical Classification System (BCS), drugs with poor aqueous solubility and high membrane permeability are classified as BCS-II category [4]. Therefore, it is always a great challenge for pharmaceutical scientists to improve the aqueous solubility as well as dissolution of these drugs for desired pharmacological effects [5] [6].

Fenofibrate (FF), a fibric acid derivative, is widely used as lipid lowering drug. It is classified as BCS-II drug and its oral absorption and bioavailability is directed by aqueous solubility that is only $0.1 \mu \mathrm{g} / \mathrm{ml}$ [7] [8] [9] [10]. To overcome this limitation, large number of investigations had been conducted. Some reported approaches are development of self-microemulsifying drug delivery system [11] [12], impregnation of drug into various silica [13] [14] [15], impact of fillers [16], oral push-pull osmotic pump [17], electrosprayed nanospherules [18], nanosuspension [19], solid dispersion [10] [20] [21], nanoparticles formations [22], anti-solvent precipitation technique [23], a pair of side by side diffusion cells [24], holt-melt extrusion [25], core shell dual mesoporous silica nanoparticles [28], nanocomposites [26] [27], dry suspension and dry emulsion [28], controlled release matrix [29], lipidic dispersion [30] and co-crystals formation [31]. Among these physical methods, solid dispersion (SD) formulation is comparatively more popular because of its high drug loading capacity and no agglomeration tendency of particles [20] [32]. Hence, solid dispersion were prepared by using a number of comprehensive carriers like mesoporous silica, clay, lactose, macroporous gelatin, octenyl succinic anhydride, polyvinylpyrrolidone, hydroxypropyl- $\beta$-cyclodextrin, sodium lauryl sulfate, pluronic F-127 and polyethylene glycol (PEG) [14] [15] [21] [22] [23] [26] [27] [28] [29]. But, PEG and silica are attractive for low melting property, less toxicity, greater hydrophilicity, wide drug compatibility, greater dissolution rate and stability of formulation [9] [33] [34].

Although many SD approaches using various carriers have been examined, but there is no report regarding the use of blend of silica and PEG on dissolution property of FF. Therefore, the objective of this work was to improve the dissolution of FF, using blend of Carplex-80 and PEG-4000 at various weight ratio using solvent evaporation method.

\section{Materials and Methods}

\subsection{Materials}

FF was a generous gift from Square Pharmaceuticals Ltd. Pabna, Bangladesh. Carplex-80 and PEG-4000 were purchased from Evonik Pvt. Ltd. Hanua, Germany. Acetone was purchased from Merck, Germany. All other reagents used were of analytical grade. 


\subsection{Preparation of SDFs}

SDFs with different weight ratio of drug and carrier (Table 1) were prepared by solvent evaporation method. The resultant SDFs were further dried in vacuum for 24 hours. Finally, these were passed through 120 mesh screen to get dried granules of uniform size. Thus, seven SDFs namely SDF1, SDF2, SDF3, SDF4, SDF5, SDF6 and SDF7 were formulated. All the formulations were stored in desiccators for further investigations.

\subsection{Determination of Drug Content}

The amount of FF in the SDFs was estimated by UV-spectrophotometric method. Briefly, an accurately weighed amount of SDFs equivalent to $25 \mathrm{mg}$ FF was dissolved in $100 \mathrm{ml}$ of methanol. Then the solution was filtered and $5 \mathrm{ml}$ of filtrate was diluted to $50 \mathrm{ml}$ with methanol to obtain a theoretical concentration 25 $\mu \mathrm{g} / \mathrm{ml}$. The drug content was assayed by comparing with a standard solution of pure FF in methanol using UV mini-1240, Shimadzu at $\lambda_{\max } 286 \mathrm{~nm}$.

\subsection{In-Vitro Dissolution Study}

In-vitro dissolution study was performed for both pure FF and all SDFs according to paddle method (USP Apparatus II) using a dissolution tester (Tianjin Guoming Medicinal Equipment Co., Ltd.). Demineralised (DM) water was used as dissolution medium. The paddle speed and temperature were maintained at $50 \pm 2 \mathrm{rpm}$ and $37.0^{\circ} \mathrm{C} \pm 0.5^{\circ} \mathrm{C}$, respectively. The analyte samples $(2 \mathrm{ml}$ each $)$ were withdrawn and transferred to $25 \mathrm{ml}$ volumetric flasks after 5, 15, 30, 60, 90, and $120 \mathrm{~min}$ interval, followed by the replacement of an equal volume of fresh medium. Concentration of FF of the filtrate at each sampling point was assayed against known concentration of FF standard with UV mini-1240, Shimadzu at $286 \mathrm{~nm}\left(\lambda_{\max }\right)$. Three replicates of each measurement were carried out and mean value was calculated to obtain dissolution profile.

\subsection{Solid-State Characterization of SDFs}

\subsubsection{Differential Scanning Calorimetry (DSC)}

Thermograms of different samples (FF, Carplex-80, PEG-4000, blend of Carplex-80

Table 1. Composition and drug content of formulated SDFs.

\begin{tabular}{cccc}
\hline Formulation code & Drug: Carrier & Weight ratio & Drug content (\%) \\
\hline SDF1 & FF: Carplex-80 & $1: 1$ & 93.2 \\
SDF2 & FF: Carplex-80 & $1: 2$ & 92.7 \\
SDF3 & FF: Carplex-80 & $1: 3$ & 95.0 \\
SDF4 & FF: PEG-4000 & $1: 1$ & 92.9 \\
SDF5 & FF: PEG-4000 & $1: 3$ & 91.7 \\
SDF6 & FF: PEG-4000 & $1: 5$ & 92.3 \\
SDF7 & FF: PEG-4000: Carplex-80 & $1: 5: 6$ & 93.6 \\
\hline
\end{tabular}


\& PEG-4000, SDF1, SDF6, and SDF7) were obtained from DSC (Exstar, SII DSC7020). Briefly, samples (3 - $5 \mathrm{mg}$ ) were placed in sealed standard aluminium pans and heated from $0^{\circ} \mathrm{C}$ to $300^{\circ} \mathrm{C}$, at a scanning rate of $10^{\circ} \mathrm{C} / \mathrm{min}$, under nitrogen purge, with an empty aluminium pan as reference.

\subsubsection{Powder X-Ray Diffractometer (PXRD)}

An X-ray diffractometer (RAD-C, Rigaku Denki Co., Ltd.) was used for the diffraction studies. The samples were exposed to $\mathrm{CuKa}$ radiation $(30 \mathrm{kV}, 50 \mathrm{~mA})$ and scanned from $2^{\circ} \mathrm{C}-40^{\circ}, 2 \theta$ at a scanning rate of $5^{\circ} / \mathrm{min}$. Samples used for PXRD analysis were FF, Carplex-80, PEG-4000, blend of Carplex-80 \& PEG-4000, SDF1, SDF6, and SDF7.

\subsubsection{Fourier Transform Infrared Spectroscopy (FTIR)}

FF, Carplex-80, PEG-4000, blend of Carplex-80 \& PEG-4000, SDF1, SDF6, and SDF7 were analysed by FTIR to study incompatible interactions. In addition, to find differences in the spectra, subtractions of the spectrum of Carplex-80, PEG-4000, and blend of Carplex-80 \& PEG-4000, was calculated. The samples were measured by the diffuse reflection method using an FT-IR spectrometer (IR-Prestige 21, Shimadzu Co.).

\subsubsection{Scanning Electron Microscopy (SEM)}

A scanning electron microscope (SSX-500, Shimadzu, Japan) was used to obtain SEM micrographs of the FF, Carplex-80, PEG-4000, blend of Carplex-80 \& PEG-4000, SDF1, SDF6, and SDF7, after coating with gold/palladium in a vacuum beforehand. An accelerating voltage of $15 \mathrm{kV}$ was used.

\subsection{Statistical Analysis}

Statistical analyses were performed using Dunnett t-test for dissolution results. A probability value of $\mathrm{p}<0.001$ was considered to indicate statistical significance.

\section{Results}

\subsection{Drug Content}

FF loading capacity of all SDFs was found more than $90 \% \mathrm{w} / \mathrm{w}$ (Table 1 ). The highest drug loading was obtained from SDF3 (FF:Carplex-80 = 1:3).

\subsection{Dissolution Study}

Dissolution study was performed to evaluate the dissolution profile of formulated SDFs in comparison with pure FF. The dissolution profiles of pure FF, SDF1, SDF2 and SDF3 are summarized in Table 2. Among these formulations, although SDF2 and SDF3 showed improvement of drug dissolution (1.5-fold higher than pure FF) but, SDF-1 showed the highest (2.0-fold) drug dissolution $(\mathrm{p}<0.001)$ than that of pure FF at each sampling point. The dissolution of FF from all formulations namely SDF4, SDF5 and SDF6 was increased than that of pure FF. Among these, SDF6 provided the most significant $(\mathrm{p}<0.001)$ dissolution 
Table 2. Dissolution of FF and SDFs at various time intervals.

\begin{tabular}{ccccccc}
\hline \multirow{2}{*}{ Formulation } & \multicolumn{5}{c}{ Drug dissolved $(\mu \mathrm{g} / \mathrm{ml})$} \\
\cline { 2 - 7 } & $5 \mathrm{~min}$ & $15 \mathrm{~min}$ & $30 \mathrm{~min}$ & $60 \mathrm{~min}$ & $90 \mathrm{~min}$ & $120 \mathrm{~min}$ \\
\hline FF & $8.8 \pm 0.4$ & $12.6 \pm 0.6$ & $13.3 \pm 0.1$ & $15.0 \pm 0.1$ & $15.0 \pm 0.1$ & $15.0 \pm 0.3$ \\
SDF1 & $21.1 \pm 0.1^{*}$ & $23.9 \pm 0.1^{*}$ & $24.9 \pm 0.1^{*}$ & $26.8 \pm 0.3^{*}$ & $27.8 \pm 0.3^{*}$ & $29.7 \pm 0.2^{*}$ \\
SDF2 & $16.3 \pm 0.1^{*}$ & $18.2 \pm 0.2^{*}$ & $19.2 \pm 0.1^{*}$ & $21.1 \pm 0.2^{*}$ & $21.0 \pm 0.1^{*}$ & $22.0 \pm 0.1^{*}$ \\
SDF3 & $16.3 \pm 0.2^{*}$ & $19.2 \pm 0.2^{*}$ & $19.2 \pm 0.1^{*}$ & $21.1 \pm 0.2^{*}$ & $21.1 \pm 0.3^{*}$ & $21.9 \pm 0.3^{*}$ \\
SDF4 & $10.3 \pm 0.3^{*}$ & $12.9 \pm 0.3^{*}$ & $14.1 \pm 0.6^{*}$ & $18.2 \pm 0.3^{*}$ & $20.7 \pm 0.2^{*}$ & $23.3 \pm 0.3^{*}$ \\
SDF5 & $14.2 \pm 0.2^{*}$ & $14.6 \pm 0.3^{*}$ & $15.1 \pm 0.2^{*}$ & $17.3 \pm 0.3^{*}$ & $23.3 \pm 0.2^{*}$ & $24.8 \pm 0.1^{*}$ \\
SDF6 & $15.9 \pm 0.1^{*}$ & $18.0 \pm 0.2^{*}$ & $18.1 \pm 0.1^{*}$ & $23.2 \pm 0.2^{*}$ & $23.8 \pm 0.1^{*}$ & $26.4 \pm 0.2^{*}$ \\
SDF7 & $29.6 \pm 0.1^{* \uparrow \uparrow}$ & $30.7 \pm 0.2^{* \uparrow}$ & $34.8 \pm 0.2^{* \uparrow \uparrow}$ & $35.9 \pm 0.1^{* \uparrow}$ & $38.0 \pm 0.2^{* \uparrow \uparrow}$ & $38.3 \pm 0.5^{* \uparrow \uparrow}$ \\
\hline
\end{tabular}

Data are expressed in mean \pm SD. ${ }^{*} \mathrm{p}<0.001$ vs FF, ${ }^{\mathrm{T}} \mathrm{p}<0.001$ vs SDF 1 and ${ }^{\uparrow} \mathrm{p}<0.001$ vs SDF6.

(1.5-fold than FF) than others. Depending on these two observations a new formulation SDF7 was made using two carriers together. From newly developed formulation (SDF7) maximum drug release (2.5-fold) than pure FF was obtained. And interestingly, it can be noticed that at $5 \mathrm{~min}$ (initial sampling point) the solubility was 3.4-fold higher than that of pure FF, although at $120 \mathrm{~min}$ it was 2.5 -fold. Moreover, the dissolution improvement by SDF7 was significant ( $\mathrm{p}$ $<0.001)$ at each sampling point by 1.4 and 1.7 -fold in comparison with the dissolution profiles of SDF1 and SDF6, respectively (Figure 1 and Table 2).

\subsection{Solid-State Characterization}

\subsubsection{DSC Study}

Figure 2 depicts the thermal characteristics of pure FF, Carplex-80, PEG-4000, blend of Carplex-80 \& PEG-4000, SDF1, SDF6, and SDF7. Pure FF generated a sharp endothermic peak at approximately $84^{\circ} \mathrm{C}$ corresponding to its melting point, indicating the crystalline nature. Carplex- 80 showed no endothermic peak, but PEG- 4000 had a sharp peak at $59.65^{\circ} \mathrm{C}$. The mixture of PEG-4000 and Carplex- 80 produced a peak with low intensity at $56.23^{\circ} \mathrm{C}$ corresponding to the peak of PEG-4000 indicating a partial physicochemical interaction between them.

Two narrow endothermic peaks corresponding to that of $\mathrm{FF}\left(84^{\circ} \mathrm{C}\right)$ could be observed with low intensity by SDF1 and SDF6, indicating minor changes in crystalline behaviour of FF. However, no peak for FF could be observed in the thermogram of SDF7 except for the mixed carrier, signifying that FF might be completely transformed into amorphous state.

\subsubsection{PXRD Study}

Figure 3 expresses the X-ray diffraction patterns of pure FF, Carplex-80, PEG-4000, blend of Carplex-80 \& PEG-4000, SDF1, SDF6, and SDF7. As a crystalline compound, FF furnished a series of sharp peaks with high intensity at $2 \theta$ angles $12.0^{\circ}, 14.46^{\circ}, 16.26^{\circ}, 16.72^{\circ}, 19.3^{\circ}, 20.9^{\circ}, 22.22^{\circ}, 24.74^{\circ}$ and $26.24^{\circ}$. Carplex- 80 


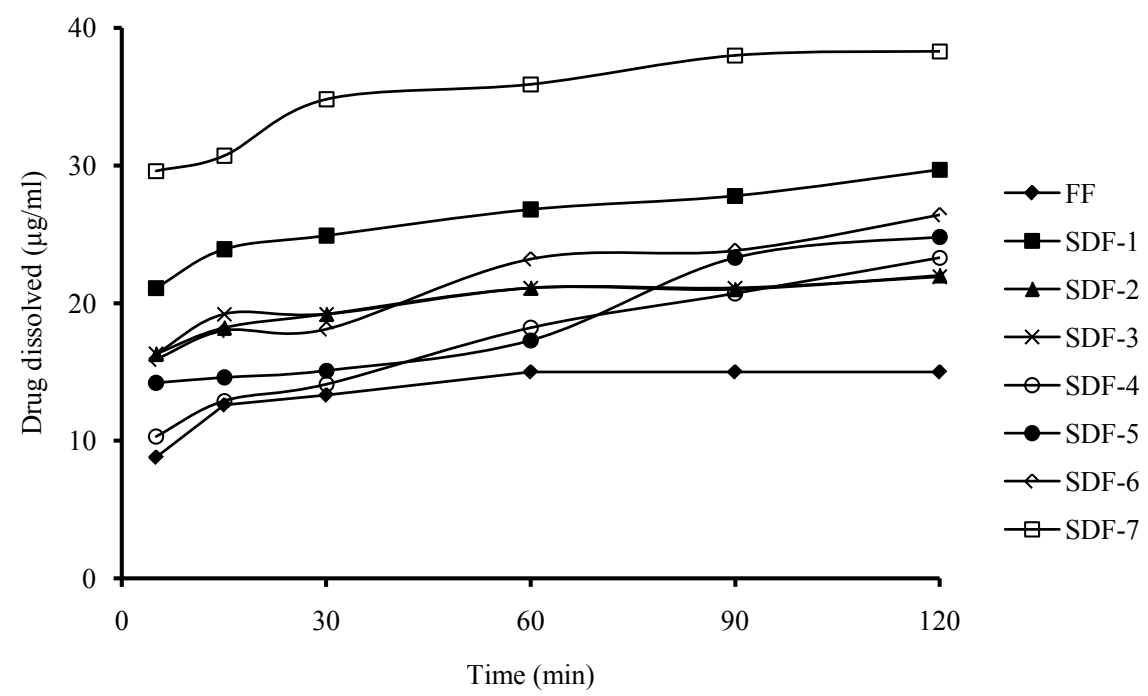

Figure 1. In-vitro comparative drug dissolution profiles of FF and SDFs.

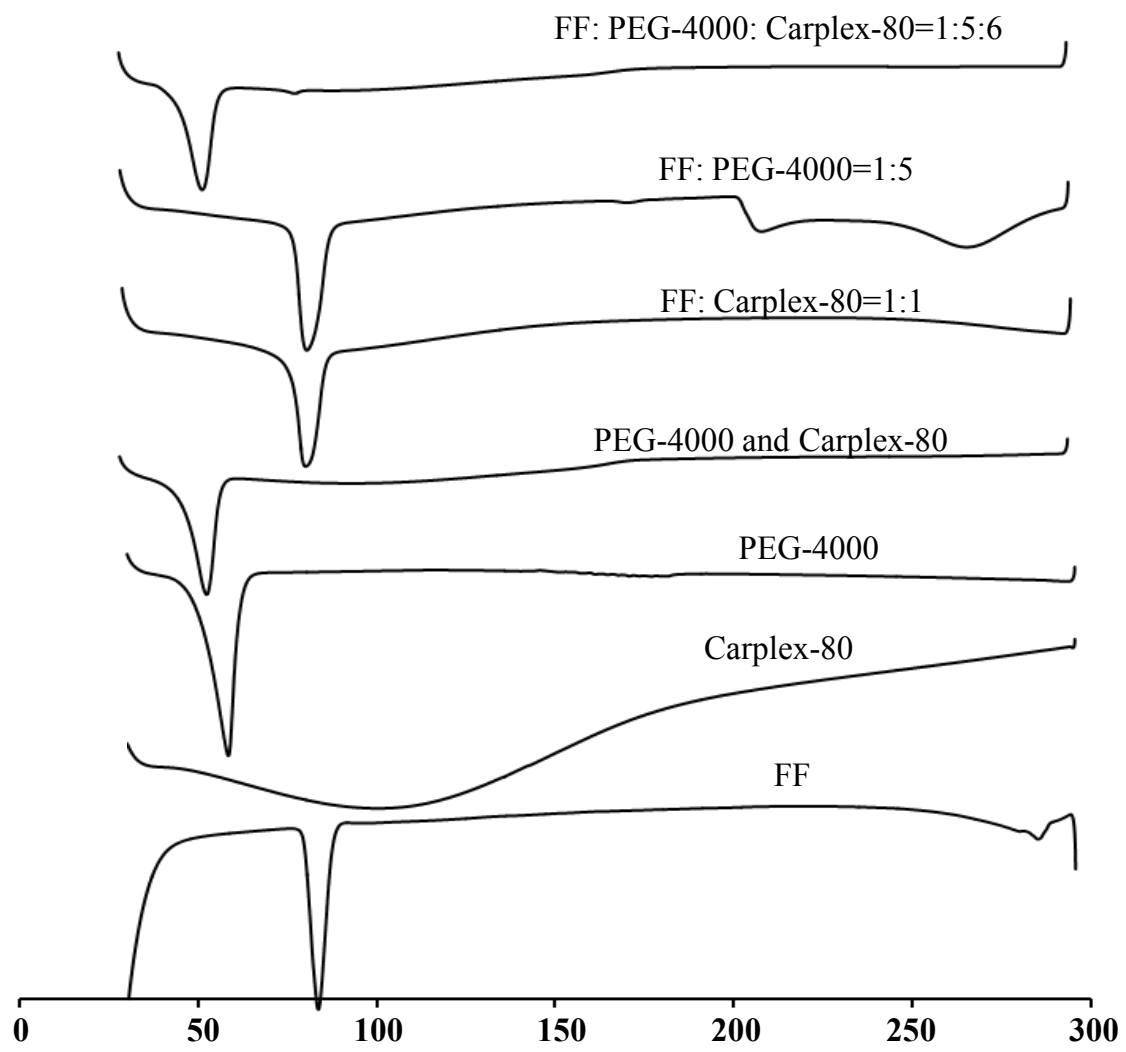

Figure 2. DSC thermograms of pure FF, Carplex-80, PEG-4000, mixture of PEG-4000 and Carplex-80, SDF-1 (FF: Carplex-80 = 1:1), SDF-6 (FF: PEG-4000 = 1:5), and SDF-7 (FF: PEG-4000: Carplex-80 = 1:5:6).

showed no peaks for crystallinity. But PEG-4000 had two intense sharp peaks at $19.44^{\circ}$ and $23.7^{\circ}$. The blend of Carplex- 80 and PEG-4000 demonstrated two dull peaks corresponding to that of PEG-4000 but with low intensity indicating a physical or weak chemical interaction. FF separately formulated with Carplex- 80 
(SDF1) and PEG-4000 (SDF6) presented some sharp peaks at $16.98^{\circ}, 22.32^{\circ}$, $22.68^{\circ}, 25.12^{\circ}, 26.76^{\circ}$ and at $12.22^{\circ}, 16.84^{\circ}, 22.26^{\circ}, 22.32^{\circ}, 26.4^{\circ}$, respectively, corresponding to that of pure FF. Elimination of other peaks at $12.0^{\circ}, 14.46^{\circ}$, $16.26^{\circ}, 19.3^{\circ}, 20.9^{\circ}$ and $14.46^{\circ}, 16.26^{\circ}, 19.3^{\circ}, 20.9^{\circ}$ by SDF1 and SDF6, respectively, indicated the partial conversion of drug crystals to amorphous state. However, no peaks corresponding to FF were found in SDF7 suggesting the inclusive transformation of drug crystal to amorphous form.

\subsubsection{FTIR Study}

The compatibility study of pure FF, Carplex-80, PEG-4000, blend of Carplex-80 \& PEG-4000, SDF1, SDF6, and SDF7 was performed by FT-IR study (Figure 4). FF produced major distinguishing peaks at 1730 (due to the ester group), 1651 (due to $\mathrm{C}=\mathrm{O}$ stretching) and $1600 \mathrm{~cm}^{-1}$ (due to the lactone carbonyl group). Carplex-80 produced a broad peak at $1103.28 \mathrm{~cm}^{-1}$ might be due to $\mathrm{O}-\mathrm{H}$ group bonded with silica. PEG-4000 showed peaks at 842.89, 1111 and $2895 \mathrm{~cm}^{-1}$ possibly due to $=\mathrm{CH}_{2}, \mathrm{C}-\mathrm{O}$ and $\mathrm{O}-\mathrm{H}$ group, respectively. Peak at $1105.21 \mathrm{~cm}^{-1}$ corresponding to that of Carplex- 80 was shown by blend of PEG-4000 and Carplex-80, which abolished the peak at $2895 \mathrm{~cm}^{-1}$ for O-H group of PEG-4000, indicating that Carplex-80 had a strong chemical bonding with PEG-4000. Besides,

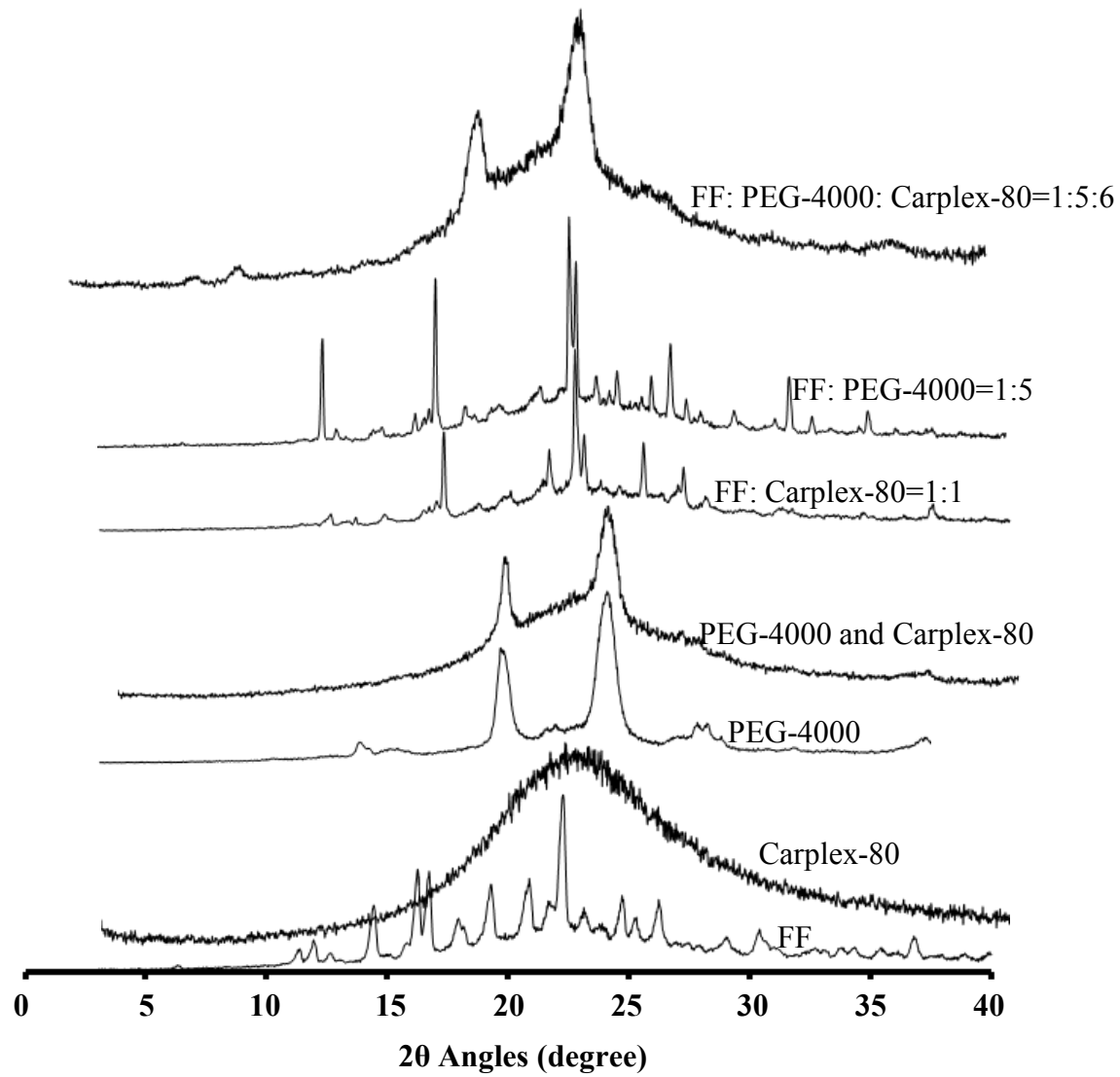

Figure 3. PXRD patterns of pure FF, Carplex-80, PEG-4000, mixture of PEG-4000 and Carplex-80, SDF-1 (FF: Carplex-80 = 1:1), SDF-6 (FF: PEG-4000 = 1:5), and SDF-7 (FF: PEG-4000: Carplex-80 = 1:5:6). 


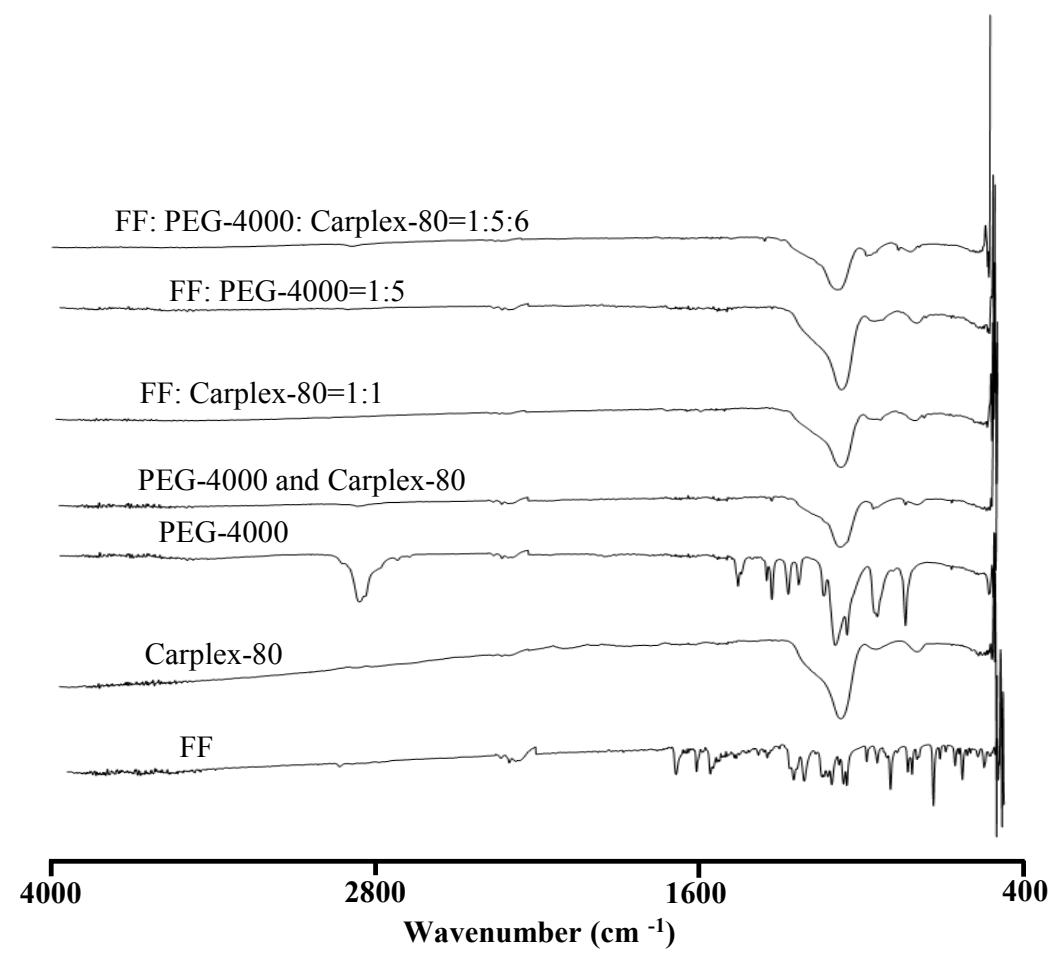

Figure 4. FTIR spectra of pure FF, Carplex-80, PEG-4000, mixture of PEG-4000 and Carplex-80, SDF-1 (FF: Carplex-80 = 1:1), SDF-6 (FF: PEG-4000 = 1:5), and SDF-7 (FF: PEG-4000: Carplex-80 = 1:5:6).

SDF1, SDF6 and SDF7 demonstrated peaks at same frequency $\left(1101 \mathrm{~cm}^{-1}\right)$ corresponding to that of Carplex-80 with varying in shapes and intensity, suggesting that either the formation of weak bond by FF with blend of carriers or chemical adsorption of FF onto surface of the blend was occurred which facilitate level of dissolution improvement of the drug. In spectra of SDF7 no peak within the range of $2700-3300 \mathrm{~cm}^{-1}$ was observed suggesting the possibility of $\mathrm{O}-\mathrm{H}$ bridging between $\mathrm{C}=\mathrm{O}$ of FF and $\mathrm{O}-\mathrm{H}$ of PEG-4000. This might be one of the key mechanisms for highly significant dissolution improvement by SDF7.

\subsubsection{SEM Study}

The SEM images of FF, Carplex-80, PEG-4000, blend of Carplex-80 \& PEG-4000, SDF1, SDF6, and SDF7 are demonstrated in Figure 5. The micrograph of the drug exhibited the presence of a crystalline solid. Carplex- 80 appeared with discrete and smooth surfaces. PEG-4000 exhibited as large crystal. In the blend of Car plex-80 \& PEG-4000, the crystalline nature of PEG-4000 was abolished and formed new smooth surfaces probably due to the interaction between $\mathrm{O}-\mathrm{H}$ group of Carplex-80 and of PEG-4000. The SEM images of SDF1 and SDF6 exhibited their surface morphology discrete and regular in shape that might be responsible for solubility improvement of FF. But, SDF7 presented a SEM image not only with discrete and regular surface morphology but also smooth surfaces that ensured the absence of drug on it; rather the drug is entrapped within the blend of carriers. 


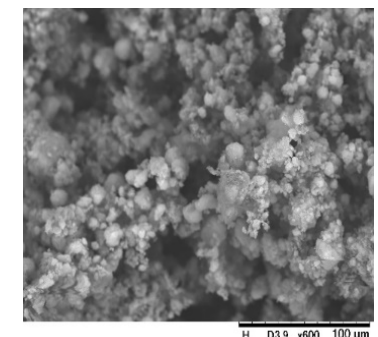

FF: PEG-4000: Carplex-80=1:5:6

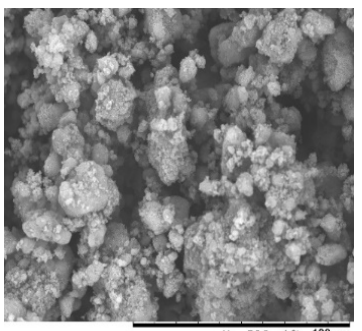

PEG-4000 and Carplex-8.0.100

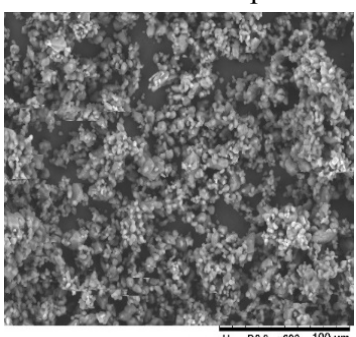

FF

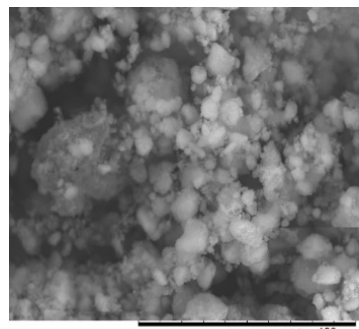

FF:Carplex $-80^{H}=1^{3.8}: 1^{2}$

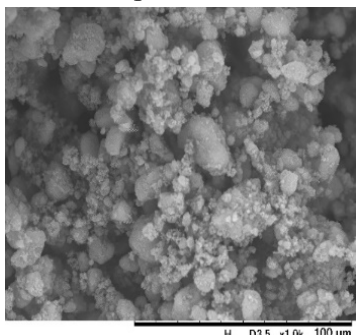

Carplex- 80

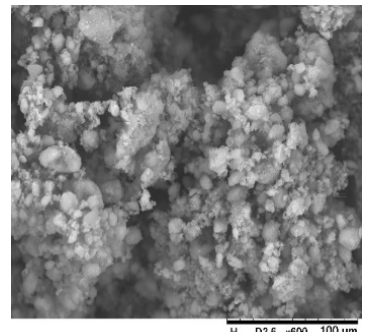

FF: PEG-400 $001: 5$

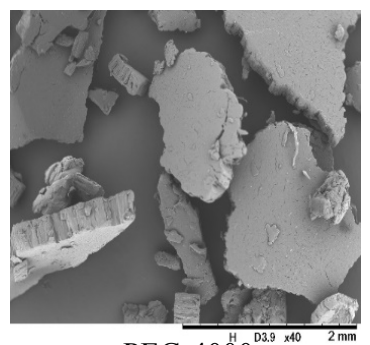

PEG-4000

Figure 5. SEM images of pure FF, Carplex-80, PEG-4000, mixture of PEG-4000 and Carplex-80, SDF-1 (FF: Carplex-80 = 1:1), SDF-6(FF: PEG-4000 = 1:5), and SDF-7 (FF: PEG-4000: Carplex-80 = 1:5:6).

\section{Discussion}

Fenofibrate is a BCS Class II drug having very poor aqueous solubility that plays a limiting role on its bioavailability [35]. To overcome this limitation solid dispersion technique was used to enhance the dissolution and oral bioavailability of hydrophobic drugs [18] [22].

The drug loading in the prepared SDFs was within the range of $91.7 \%-95.0 \%$. Our result resembled with the study of Harendra Prasad et al., who reported the percent of drug content in SDFs prepared by solvent evaporation method [36] [37]. In our study, the most significant $(\mathrm{p}<0.001)$ improvement of drug dissolution initially after $5 \mathrm{~min}$ and after $120 \mathrm{~min}$ was obtained by SDF7, which might be a noticeable improvement than that of pure FF at corresponding sampling points. The improved dissolution of FF might be due to achieving the higher level of wettability by PEG-4000 and entrapment of drug molecules by the blend of carriers converting the drug crystals to amorphous form which was authenticated together with DSC thermograms, PXRD data and surface morphology studies by SEM. Another possibility for this conversion might be the polymorphic transformation by reducing $\mathrm{T}_{\mathrm{g}}$ (glass transition temperature) of PEG-4000 [38], which might be one of the causes of enhanced dissolution that also reported in 
previous studies [21] [39] [40]. The anticipated mechanism for increased wettability of the drug might be noticed as a strong interaction of silica with PEG-4000 and formation of reversible chemical bonding by FF with Carplex-80, suggesting the improvement of wettability property of the drug, which resulted its improved dissolution [41] [42] [43].

Finally, taken together with DSC, PXRD, FTIR and SEM results it is revealed that the crystalline behaviour of FF was abolished using the combination of Carplex-80 and PEG-4000 as carriers. Thus, the enhanced dissolution profiles of SDFs correspond with transformation of drug from crystalline to amorphous state. Therefore, the formulation SDF7 can be designated as the best formulation for dissolution enhancement of FF considering its dissolution study, DSC, PXRD, FTIR and SEM.

\section{Conclusion}

This study reveals the significant improvement of dissolution of FF that is mainly attributed to the use of carriers blend (FF:PEG-4000:Carplex-80 = 1:5:6). Therefore, solid dispersion of fenofibrate, thus prepared, would be promising for oral drug delivery of fenofibrate with enhanced drug dissolution performance.

\section{Acknowledgements}

We acknowledge the Department of Pharmaceutical Engineering, School of Pharmaceutical Sciences, University of Shizuoka, Shizuoka, Japan for DSC, PXRD, FTIR and SEM analysis.

\section{Conflicts of Interest}

The authors declare that there is no conflict of interest regarding this research work.

\section{References}

[1] Emamai, S., Valizadeh, H., Islambulchilar, Z. and Zakeri-Milani, P. (2014) Development and Physicochemical Characterization of Sirolimus Solid Dispersions Prepared by Solvent Evaporation Method. Advanced Pharmaceutical Bulletin, 4, 269-374.

[2] Varshosaz, J. and Ghassami, E. (2015) Enhancement of Dissolution Rate of Fenofibrate by Spray Drying Technique: Comparison of Eudragit E-100, Solutol HS15 and Hydroxypropyl Cellulose as Carriers. Farmacia, 63, 433-445.

[3] Anjana, M.N., Joseph, J. and Nair, S.C. (2013) Solubility Enhancement Methods-A Promising Technology for Poorly Water Soluble Drugs. International Journal of Pharmaceutical Sciences Review and Research, 20, 127-134.

[4] Humayouni, A., Sadeghi, F., Nokhodchi, A., Varshosaz, J. and Garekani, H.A. (2014) Preparation and Characterization of Celecoxib Solid Dispersions; Comparison of Poloxamer-188 and PVP-K30 as Carriers. Iranian Journal of Basic Medical Sciences, 17, 322-331. 
[5] Verma, S. and Rudraraju, V.S. (2015) Wetting Kinetics: An Alternative Approach towards Understanding Enhanced Dissolution Rate for Amorphous Solid Dispersion of a Poorly Soluble Drug. AAPS PharmSciTech, 16, 1079-1090. https://doi.org/10.1208/s12249-014-0281-x

[6] Zakeri-Milani, P., Nezhadi, S.H., Barzegar-Jalali, M., Mohammadi, L., Nokhodchi, A. and Valizadeh, H. (2011) Studies on Dissolution Enhancement of Prednisolone, a Poorly Water Soluble Drug by Solid Dispersion Technique. Advanced Pharmaceutical Bulletin, 1, 48-53.

[7] Berthelsen, R., Sjögren, E., Jacobsen, J., Kristensen, J., Holm, R., Abrahamsson, B. and Müllertz, A. (2014) Combining in Vitro and in Silico Methods for Better Prediction of Surfactant Effects on the Absorption of Poorly Water Soluble Drugs-A Fenofibrate Case Example. International Journal of Pharmaceutics, 473, 356-365. https://doi.org/10.1016/j.ijpharm.2014.06.060

[8] Tziomalos, K. and Athyros, V.G. (2006) Fenofibrate: A Novel Formulation (Triglide $\left.^{\mathrm{Tm}}\right)$ in the Treatment of Lipid Disorders: A Review. International Journal of Nanomedicine, 1, 129-147. https://doi.org/10.2147/nano.2006.1.2.129

[9] Vinay, V.N.V., Venkatesh, K., Phanindra, K., Keerthi, S. and Swetha, K. (2012) Formulations and Evaluations of Solid Dispersions of Fenofibrate for Dissolution Rate Enhancement. Journal of Chemical and Pharmaceutical Research, 4, 4752-4756.

[10] Karolewicz, B., Gajda, M., Pluta, J. and Gorniak, A. (2016) Dissolution Study and Thermal Analysis of Fenofibrate-Pluronic F127 Solid Dispersions. Journal of Thermal Analysis and Calorimetry, 125, 751-757. https://doi.org/10.1007/s10973-015-5013-2

[11] Cho, Y.D. and Park, Y.J. (2014) In Vitro and in Vivo Evaluation of a Self-Microemulsifying Drug Delivery System for the Poorly Soluble Drug Fenofibrate. Archives of Pharmacal Research, 37, 193-203. https://doi.org/10.1007/s12272-013-0169-4

[12] Kim, G.G., Poudel, B.K., Marasini, N., Lee, D.W., Hiep, T.T., Yang, K.Y., Kim, J.O., Yong, C.S. and Choi, H.G. (2013) Enhancement of Oral Bioavailability of Fenofibrate by Solid Self-Microemulsifying Drug Delivery Systems. Drug Development and Industrial Pharmacy, 39, 1431-1438. https://doi.org/10.3109/03639045.2012.719903

[13] Speybroecka, M.V., Mellaertsb, R., Molsa, R., Thia, T.D., Martensb, J.A., Humbeeckc, J.V., Annaerta, P., Mootera, G.V.D. and Augustijnsa, P. (2010) Enhanced Absorption of the Poorly Soluble Drug Fenofibrate by Tuning Its Release Rate from Ordered Mesoporous Silica. European Journal of Pharmaceutical Sciences, 41, 623-630. https://doi.org/10.1016/j.ejps.2010.09.002

[14] Azad, M., Moreno, J. and Dave, R. (2018) Stable and Fast-Dissolving Amorphous Drug Composites Preparation via Impregnation of Neusilin UFL2. Journal of Pharmaceutical Sciences, 107, 170-182. https://doi.org/10.1016/j.xphs.2017.10.007

[15] Bouledjouidja, A., Masmoudi, Y., Van, S.M., Schueller, L. and Badens, E. (2016) Impregnation of Fenofibrate on Mesoporous Silica Using Supercritical Carbon Dioxide. International Journal of Pharmaceutics, 499, 1-9. https://doi.org/10.1016/j.ijpharm.2015.12.049

[16] Lenz, E., Sprunk, A., Kleinebudde, P. and Page, S. (2014) Impact of Fillers on Dissolution Kinetic of Fenofibrate Dry Foams. Pharmaceutical Development and Technology, 20, 570-578. https://doi.org/10.3109/10837450.2014.908301

[17] Zhao, Z., Wu, C., Zhao, Y., Hao, Y., Liu, Y. and Zhao, W. (2015) Development of an 
Oral Push-Pull Osmotic Pump of Fenofibrate-Loaded Mesoporous Silica Nanoparticles. International Journal of Nanomedicine, 10, 1691-1701. https://doi.org/10.2147/IJN.S76755

[18] Yousaf, A.M., Mustapha, O., Kim, D.W., Kim, D.S., Kim, K.S., Jin, S.G., Yong, C.S., Youn, Y.S., Oh, Y.K. and Kim, J.O. (2016) Novel Electrosprayed Nanospherules for Enhanced Aqueous Solubility and Oral Bioavailability of Poorly Water-Soluble Fenofibrate. International Journal of Nanomedicine, 11, 213-221. https://doi.org/10.2147/IJN.S97496

[19] Dong, Y., Ng, W.K., Hu, J., Shen, S. and Tan, R.B. (2014) Clay as a Matrix Former for Spray Drying of Drug Nanosuspensions. International Journal of Pharmaceutics, 465, 83-89. https://doi.org/10.1016/j.ijpharm.2014.02.025

[20] Singh, A., Worku, Z.A. and Mooter, G.V. (2011) Oral Formulation Strategies to Improve Solubility of Poorly Water-Soluble Drugs. Expert Opinion on Drug Delivery, 8, 1361-1378. https://doi.org/10.1517/17425247.2011.606808

[21] Irwan, A.W., Berania, J.E. and Liu, X. (2016) A Comparative Study of the Effects of Amphiphilic and Hydrophilic Polymers on the Release Profiles of a Poorly Water-Soluble Drug. Pharmaceutical Development and Technology, 21, 231-238. https://doi.org/10.3109/10837450.2014.991877

[22] Yousaf, A.M., Kim, D.W., Oh, Y.K., Yong, C.S., Kim, J.O. and Choi, H.G. (2015) Enhanced Oral Bioavailibility of Fenofibrate Using Polymeric Nanoparticulated Systems: Physicochemical Characterization and in Vivo Investigation. International Journal of Nanomedicine, 10, 1819-1830. https://doi.org/10.2147/IJN.S78895

[23] Tierney, T., Bodnar, K., Rasmuson, A. and Hudson, S. (2017) Carrier Particle Design for Stabilization and Isolation of Drug Nanoparticles. International Journal of Pharmaceutics, 518, 111-118. https://doi.org/10.1016/j.ijpharm.2016.11.045

[24] Sironi, D., Rosenberg, J., Bauer-Brandi, A. and Brandi, M. (2017) Dynamic Dissolution-/Permeation-Testing of Nano- and Microparticle Formulations of Fenofibrate. European Journal of Pharmaceutical Sciences, 96, 20-27. https://doi.org/10.1016/j.ejps.2016.09.001

[25] Patil, H., Feng, X., Ye, X., Majumdar, S. and Repka, M.A. (2015) Continuous Production of Fenofibrate Solid Lipid Nanoparticles by Hot-Melt Extrusion Technology: A Systematic Study Based on a Quality by Design Approach. AAPS Journal, 17, 194-205. https://doi.org/10.1208/s12248-014-9674-8

[26] Zhao, Z., Gao, Y., Wu, C., Hao, Y., Zhao, Y. and Xu, J. (2016) Development of Novel Core-Shell Dual-Mesoporous Silica Nanoparticles for the Production of High Bioavailable Controlled-Release Fenofibrate Tablets. Drug Development and Industrial Pharmacy, 42, 199-208. https://doi.org/10.3109/03639045.2015.1039018

[27] Azad, M., Moreno, J., Bilgili, E. and Davé, R. (2016) Fast Dissolution of Poorly Water Soluble Drugs from Fluidized Bed Coated Nanocomposites: Impact of Carrier Size. International Journal of Pharmaceutics, 513, 319-331. https://doi.org/10.1016/j.ijpharm.2016.09.046

[28] Progsamrat, K., Kleinebudde, P. and Puttipipatkhachorn, S. (2016) Preparation of Fenofibrate Dry Emulsion and Dry Suspension Using Octenyl Succinic Anhydride Starch as Emulsifying Agent and Solid Carrier. International Journal of Pharmaceutics, 498, 347-354. https://doi.org/10.1016/j.ijpharm.2015.12.041

[29] Wu, Q.L., Quan, G.L., Hong, Y., Wu, L.N., Zeng, Y.M., Li, G., Pan, X. and Wu, C.B. (2015) Preparation and Release Behaviour of Mesoporous Silica/Ethyl Cellulose Sustained-Release Mini-Matrix. Acta Pharmaceutica Sinica, 50, 492-499.

[30] O’Shea, J.P., Faisal, W., Ruane-O’Hora, T., Devine, K.J., Kostewicz, E.S., O’Driscoll, 
C.M. and Griffin, B.T. (2015) Lipidic Dispersion to Reduce Food Dependent Oral Bioavalibility of Fenofibrate: In Vitro, in Vivo and in Silico Assessments. European Journal of Pharmaceutics and Biopharmaceutics, 96, 207-216. https://doi.org/10.1016/j.ejpb.2015.07.014

[31] Shewale, S., Shete, A.S., Doijad, R.C., Kadam, S.S., Patil, V.A. and Yadav, A.V. (2015) Formulation and Solid State Characterization of Nicotinamide-Based Co-Crystals of Fenofibrate. Indian Journal of Pharmaceutical Sciences, 77, 328-334. https://doi.org/10.4103/0250-474X.159669

[32] Huang, Y. and Dai, W.G. (2014) Fundamental Aspects of Solid Dispersion Technology for Poorly Soluble Drugs. Acta Pharmaceutica Sinica B, 4, 18-25. https://doi.org/10.1016/j.apsb.2013.11.001

[33] Handa, U. and Saroha, K. (2018) Research and Development of Diazepam Solid Dispersion Powder Using Natural Polymer. International Journal of Pharmaceutics, 10, 220-225. https://doi.org/10.22159/ijap.2018v10i5.27975

[34] Patel, V.I. and Dave, R.H. (2013) Evaluation of Colloidal Solid Dispersions: Physiochemical Considerations and In-Vitro Release Profile. AAPS PharmSciTech, 14, 620-628. https://doi.org/10.1208/s12249-013-9947-z

[35] Tran, T.H., Ramasamy, T., Truong, D.H., Choi, H.G., Yong, C.S. and Kim, J.O. (2014) Preparation and Characterization of Fenofibrate Loaded Nano Structured Lipid Carriers for Oral Bioavailability Enhancement. AAPS PharmSciTech, 15, 1509-1515. https://doi.org/10.1208/s12249-014-0175-y

[36] Prasad, H. and Verma, N.K. (2014) Development and Evaluation of Solid Dispersion of Fenofibrate Using Polyethyleneglycol as Carrier. Der Pharmacia Lettre, 6, 63-69.

[37] Prasad, H. and Verma, N.K. (2014) Dissolution Enhancement of Fenofibrate Solid Dispersion Prepared Using Hydrophilic Carriers by Solvent Evaporation Method. Journal of Medical and Pharmaceutical Innovation, 1, 16-20.

[38] Barman, R.K., Iwao, Y., Funakoshi, Y., Ranneh, A.H., Noguchi, S., Wahed, M.I.I. and Itai, S. (2014) Development of Highly Stable Nifedipine Solid-Lipid Nanoparticles. Chemical and Pharmaceutical Bulletin, 62, 399-406. https://doi.org/10.1248/cpb.c13-00684

[39] Leuner, C. (2000) Improving Drug Solubility for Oral Delivery Using Solid Dispersion. European Journal of Pharmaceutics and Biopharmaceutics, 50, 47-60. https://doi.org/10.1016/S0939-6411(00)00076-X

[40] Hancock, B.C. and Parks, M. (2000) What Is the True Solubility Advantage for Amorphous Pharmaceuticals? Pharmaceutical Research, 17, 397-404. https://doi.org/10.1023/A:1007516718048

[41] Yin, L.F., Huang, S.J., Zhu, C.L., Zhang, S.H., Zhang, Q., Chen, X.J. and Liu, Q.W. (2012) In-Vitro and In-Vivo Studies on a Novel Solid Dispersion of Repaglinide Using Polyvinylpyrrolidone as the Carrier. Drug Development and Industrial Pharmacy, 38, 1371-1380. https://doi.org/10.3109/03639045.2011.652635

[42] Patel, J.R., Carlton, R.A., Yuniatine, F., Needham, T.E., Wu, L. and Vogt, F.G. (2012) Preparation and Structural Characterization of Amorphous Spray-Dried Dispersions of Tenoxicam with Enhanced Dissolution. Journal of Pharmaceutical Sciences, 101, 641-663. https://doi.org/10.1002/jps.22800

[43] Pahovnik, D., Reven, S., Grdadolnik, J., Borštnar, R., Mavri, J. and Zagar, E. (2011) Determination of the Interaction between Glimepiride and Hyperbranched Polymers in Solid Dispersions. Journal of Pharmaceutical Sciences, 100, 4700-4709. https://doi.org/10.1002/jps.22662 